\title{
Antithymocyte Globulin Rabbit/Tacrolimus Regimen
}

National Cancer Institute

\section{Source}

National Cancer Institute. Antithymocyte Globulin Rabbit/Tacrolimus Regimen. NCI

Thesaurus. Code C160505.

A regimen consisting of rabbit antithymocyte globulin and tacrolimus that can be used

for the prevention and treatment of acute rejection following org an transplantation. 